\title{
IDÉIAS
}

\section{Por um sistema dos Estados Regionais}

José Jatobá Lins ( ${ }^{\star}$



Brasil como pais de grande extensão territorial, grande diversificação e diferenciação social, econômica, cultural e politica, nas suas regiões macros e micros - chegando ao ponto de se falar em "Brasis" - carece de desenvolver seu rico regionalismo, levantando, estudando, identificando e delimitando regiöes nas esferas de governos municipais, estaduais e federais, para criar completos Estados Regionais.

O corpo institucional da Nova República sob a "democracia participativa", significará muito pouco sem a descentralização e desconcentração institucional, organizacional, administrativa e da estrutura de poder. Diluir o poder dos governos estaduais, municipais e federal é fundamental para a democratização.

O conjunto institucional e organizacional arquitetado pela Nova Republica deve buscar um modelo adaptativo, orgânico e plástico de organização para que o sistema administrativo nacional seja um articulado de sistemas integrados, "de baixo para cima", de modo a aproveitar as potencialidades regionais e locais, no amplo sentido politico, social, econômico e cultural - homogeneisando a economia, a politica e a sociedade, assegurando a unidade nacional com o conceito da centralidade democrática.

A proposta alternativa é a criação de Estados Regionais completos, nas esferas de governos. Clarificando o que se quer dizer: Presidente Regional, Senador Regional, Deputado Regional, Governador Regional, Pre-

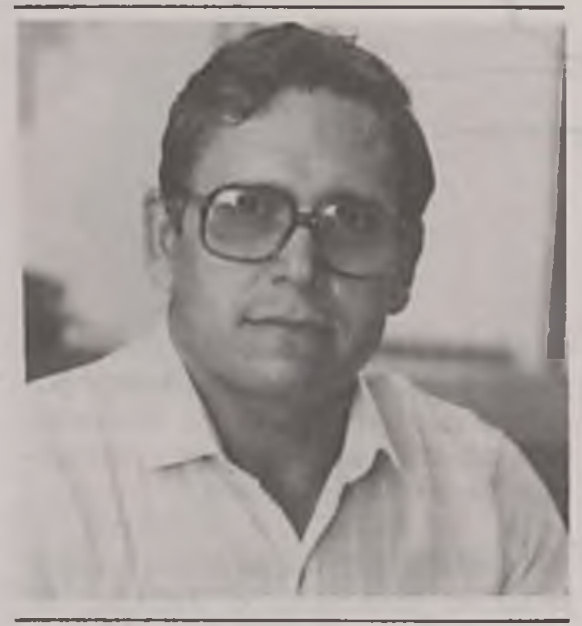

feito Regional, Vereador Regional, Câmara Regional e Assembleia Regional, Ministros Regionais e Secretários Regionais.

Evidentemente, os Estados Regionais devem nascer do conceito de regiào e regionalismo, ventilado por especialistas na matéria. Não se trata de redivisão territorial do Brasil - ou que em parte o seja, para finalidades técnicas, politicas, etc. Mas que a Região tenha como base a sua yocação natural, seu ecossistema, sua estrutura organizativa, cultural, politica e social - e fatores outros que os especialistas os quantificam e dimensionam para justificarem o estabelecimento da região.

A importancia dos Estados Regionais é, imediatamente, a distribuição do poder, a democratização politica, social e economica, o combate às desigualdades regionais e locais e às disparidades sociais.

(*) Administrador de empresa pública, com mestrado em Administração Pública, dos quadros da SEMOR/SEDAP.

A institucionalização generalizada de deliberativos regionais, abertos e participativos, levariam à criação de Conselhos de Prefeitos Regionais, Governadores Regionais e Presidentes Regionais que junto às Câmaras e Assembléias Regionais decidiriam sobre fluxos de recursos dando paridade social, económica e politica às regiōes e aos cidadões, tomando plana a economia nacional e adaptandoa às diversas realidades brasileiras, reconceituando a economia nacional. Tal comportamento dirigente traria forçosamente a homogeneidade econômica, política e social do ecossistema nacional e a integração das economias regionais à economia nacional. A administração do desenvolvimento econômico e social seria um produto da ação nacional.

Este sistema pode parecer mecanistico e fechado se visualizarmos a estrutura organizacional separada da estrutura de poder e longe do conceito de democracia participativa. Porém o sistema organizacional proposto deve ser aberto, orgânico e participativo-.-Isto é, as instancias e deliberativos decisórios devem ter bancadas percentuais suficientemente representativas das classes sociais, trabalhadoras, profissionais e de entidades públicas e privadas, para que se possa assegurar a maior participação possível, na defesa de uma verdadeira e moderna democracia.

Evidentemente, o Estado é a maior e mais poderosa organizaçāo da sociedade. Ao Estado a sociedade tem concedido o maior espectro de poderes. Dai a responsabilidade da sociedade nacional ante a constituição da Assembléia Nacional Constituinte. Porque a Lei Maior é o pacto dos pactos. Quanto maior o Estado, 


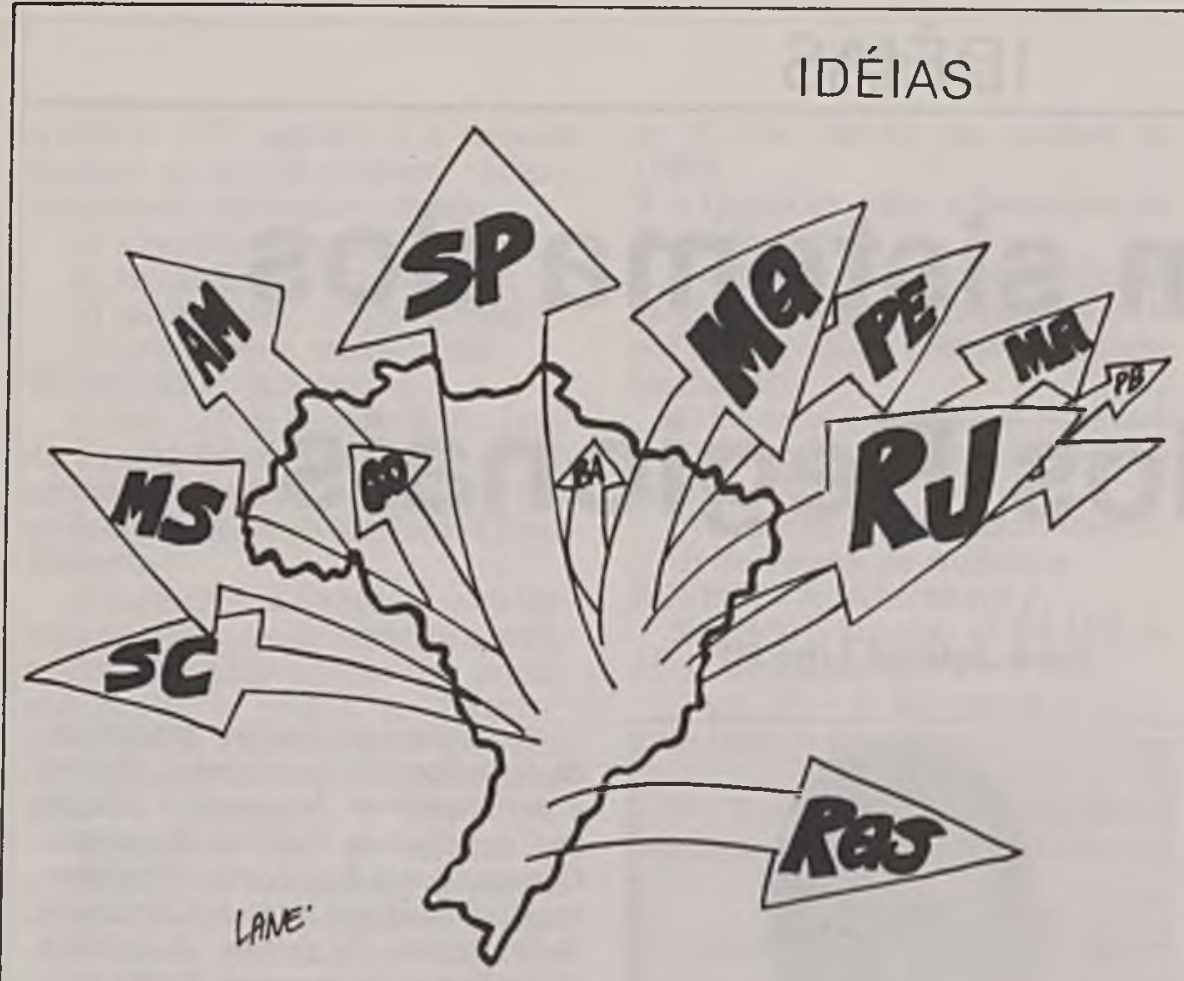

maior o poder, porque cobre uma sociedade maior.

Os poderes da sociedade nacional, regional ou local convergem para deliberativos ou parlamentos que na sua composição homogênea ou heterogênea pode ser deliberativo horizontal ou vertical. Os Conselhos deliberativos horizontais são homogèneos porque têm membros de qualidade identicas e assemelhados: Conselho de Prefeitos Regionais, Reunião de Governadores Estaduais, etc. Conselhos ou deliberativos verticais são heterogéneos porque têm $\mathrm{mem}$ bros de diferentes qualidades e dissemelhantes: Conselho de Desenvolvimento Regional: $40 \%$ de Governadores e Prefeitos, $30 \%$ de entidades de classes, sindicatos, etc. E assim, outros conselhos e Comissões, regionais, municipais, estaduais, federais, deveriam ser criadas com ampla participaçào de entidades no sistema decisorio governamental.

Se a organização nacional se fundamenta em sistemas orgânicos, adaptivos e abertos que funcionem articuladamente em todas as direçōes e dimensōes num conjunto monolitico, com centralidade democrática no governo federal, fica assegudara a unidade nacional sob o regime federativo. Um sistema de regiões autônomas, autodirigidas, auto-administradas por cidades, municipios ou

vernamentais. Porém, o planejamento e a administração serão altamente beneficiados pelo processo de descentralização e desconcentração. O planejamento estratégico ou tático serão mais eficientes e eficazes no sistema "de baixo para cima". Se os principais centros decisórios, nos quais nascem o plano forem as organizações as cidades, os municipios, os estados, e as regiōes, essa projeção no centro nacional de planejamento refletirá o planejamento participativo e democrático a nível nacional.

No caso brasileiro, a magnitude do pais levaria a grandes complexos regionais, porem o conceito de sistema aberto, organísmico e adaptativo levaria os sistemas a um funcionamento flexivel dentro dum sistema nacional flexível. As conexōes e articulações intergovernamentais, inter-regionais e interorganizacionais estabeleceriam um sistema de comunicação, informação e decisão acomodativo e adequativo que garantiria o combate às desigualdades e disparidades que são centros geradores de todos os conflitos de poder econômico, político e social.

Verdade é que a regionalizaçāo é processo complexo e trabalho de competentes especialistas. Mas o Brasil tem estes especialistas. Os fatores naturais, económicos, sociais, culturais, topológicos, geográficos, politicos, etc. darão origem a vetores que implicarão em impactos na administração e no planejamento go-

A importância dos Estados Regionais é, imediatamente, a distribuição do poder, democratização politica, social e econômica, o combate às desigualdades regionais e locais, $e$ as disparidades sociais que ocorrem em todos os niveis.
O estabelecimento do sistema de estados regionais não implica apenas em modernização do sistema institucional de poder. Todas as estruturas sofrerão impacios inovadores e modificadores, levando a sociedade a participar da administração da riqueza nacional. Os resultados do trabalho se repartirão mais perto dos agentes de produção (no local, na região), ficando os estados como coordenadores e condutores do processo de desenvolvimento de entidades públicas e privadas. Os sistemas de "fundos" procederiam a redistribuição de riquezas entre entidades combatendo as desigualdades e disparidades que afligem o sistema atual.

O Novo Pacto Social trará as diretrizes claras das estratégias que apoiarão medidas e instrumentos de decisōes que combaterão as disparidades e desigualdades regionais e sociais. O Novo Estado social da Nação brasileira concorrerá para a plena democracia através dos Planos $\mathrm{Na}$ cionais de Desenvolvimento da Nova República. 